\title{
Making Editorial Waves
}

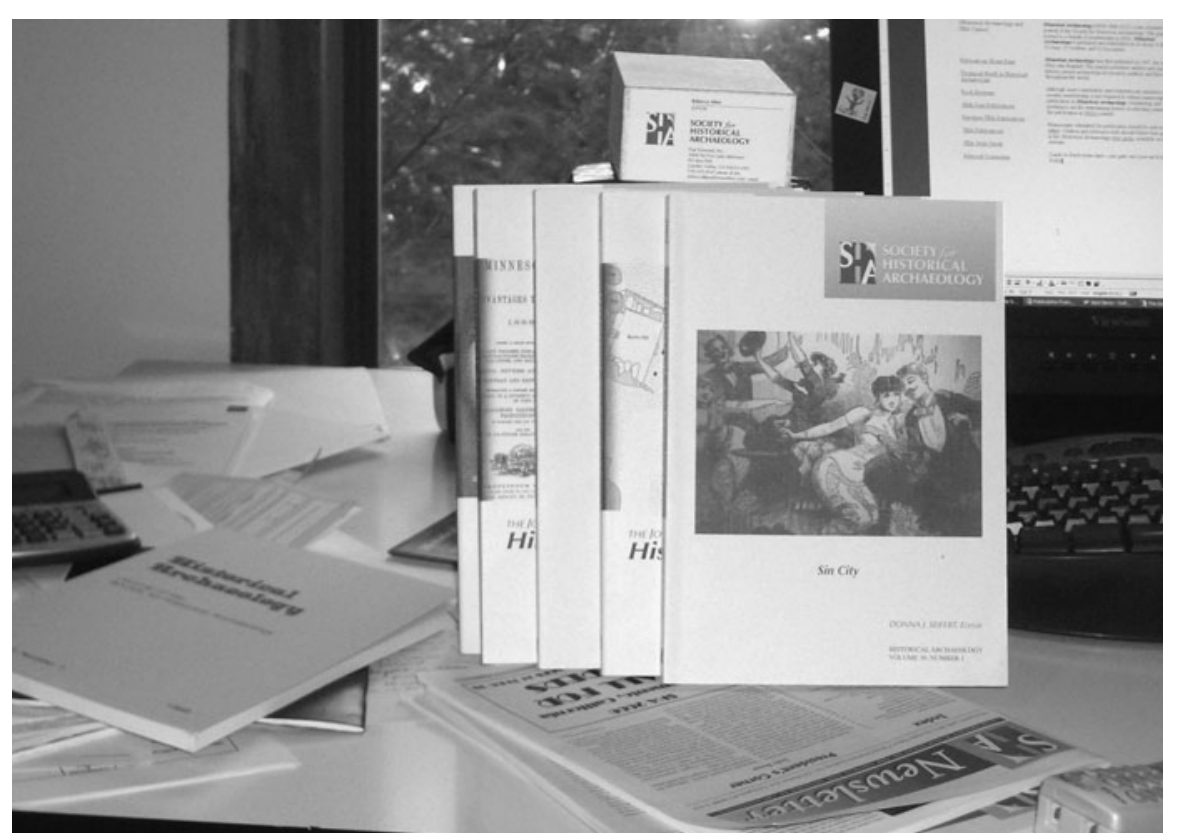

The SHA membership is remarkable in that its members publish more articles than any other society that I am familiar with. Although we are about one-quarter the size of other national and international archaeological societies, our members overfill the quarterly journal, and the Editorial Advisory Committee has been challenged to keep up. When I began my editorial term, the solid rock of historical archaeology research was in need of ripple effects to create more publishing opportunities. In response to this demand and associated responsibilities, I have worked with the EAC and the SHA Board of Directors to divide the editorial role into three: journal editor, website editor, and co-publications editor.

With this issue, I pass on the mantle of journal editor for The Society for Historical Archaeology to J.W. "Joe" Joseph. He will begin his term as journal editor in 2008, with Mary Beth Reed assisting him as co-editor. Joe has been an associate editor since 2004 and was a board director from 2005-2007. Joe and Mary Beth will also be working with Charles Ewen, reviews editor, and David V. Burley, Technical Briefs editor. Reviews are now published on the SHA website, but are listed in the table of contents of HA. In 2006, Dave Burley oversaw the creation and publication of Technical Briefs in Historical Archaeology, vol. 1, on the SHA website, and vol. 2, 2007, is already well underway. I retire knowing that SHA's flagship, Historical Archaeology, is in good hands and will continue with the publication of thematic issues and contributed articles. There is an increasing need for individually submitted articles, and I encourage all SHA members to submit articles to our journal. 
Kelly Dixon became the society's first website editor in 2006. Greg Waselkov, board liaison to the website, and I worked closely with Kelly to make SHA more prominent on the Internet. I encourage readers to visit the website at $<$ www.sha.org $>$ and become more familiar with the web-based publishing outlets that now exist, including the Research Resources, Current Projects, Underwater pages, and the more publicoriented Exploring Historical Archaeology and Unlocking the Past. The website makes available back issues of the journal, special publications, guides to literature, and underwater proceedings. Spectral Fusion, the University of Montana's host behind the SHA website, has also created powerful search engines that I am confident will transform the way that historical archaeologists can do literature research.

Rounding out the new editorial triad, Annalies Corbin became the co-publications editor at the January meeting in 2007. This rapidly growing area needed its own editor to oversee the co-publication contracts that are already in progress and to create even more publication opportunities and outlets for topics in historical archaeology. I suspect that the society's website and newsletter will soon carry more news of copublications; Annalies is already investigating the potential for print-on-demand capabilities.

Co-publications got their start under my editorial predecessor Ronald L. Michael, who established a unique co-publishing relationship with the University Press of Florida. SHA's well-received special publications and guides to literature needed a larger audience and a more cost-effective publishing mechanism. Under Ronn's aegis, SHA-UPF have published several successful volumes, reviewed by SHA and UPF editorial staff. Royalties go into the SHA publication fund, and SHA members receive a discount. Publishing graduate student work led to another cooperative venture with UPF. The SHA Dissertation Prize, created in 2001, is awarded to a recent graduate whose dissertation is considered an outstanding contribution to historical archaeology and includes a prepublication contract with UPF and a $\$ 1,000$ cash prize. James Ayres has been chair of the Dissertation
Committee nearly since its inception. SHA-UPF published the first dissertation prize topic, The Jewish Community of Early Colonial Nevis, in 2004. Currently, six more dissertation prizes are in the publication works.

Building on the UPF success, LouAnn Wurst, Ronn, and I negotiated with the University of Nebraska Press to create co-publishing agreements on western topics in historical archaeology and material culture. To date, three contracts have been signed, and we hope to see the first SHA-UNP volume published next year.

In April 2007, the Society for American Archaeology, in cooperation with SHA, published Witness to the Past: The Life and Works of John L. Cotter. David G. Anderson, the SAA Press editor who guided the publication, and I were inspired by Cotter's ability to bridge our two disciplines and offer an anthropological perspective in both fields. Edited by Daniel G. Roberts and David G. Orr, the selected articles highlight John Cotter's career in prehistoric, historical, and public archaeology.

Collectively, editorial activities of the journal, website, and co-publications are the result of more than 4,000 hours of volunteer time annually. The SHA publication program is an astonishing volunteer feat that demonstrates the dedication of society Editorial Advisory Committee members. The inside cover of each journal issue and the website lists their names, a list too long to repeat here, but I hope that each EAC member knows that I have been privileged to have their support, guidance, and encouragement. I have especially benefited from the wisdom and humor of Ronn Michael, Greg Waselkov, and Sara Mascia. I am very fortunate to have worked with copy editor Marianne Brokaw and Terry Sherrell at Morgan Printing. I will retire as editor with a large debt of gratitude to all of these individuals. In the interim, I look forward to having the time to tidy up my office.

\section{Rebecca Allen}

PAST FoRWARD, InC.

PO Box 969

Garden Valley, CA 95633 